\title{
Preterm twin gestation and cystic periventricular leucomalacia
}

\author{
B Resch, A Jammernegg, E Vollaard, U Maurer, W D Mueller, B Pertl
}

Arch Dis Child Fetal Neonatal Ed 2004;89:F315-F320. doi: 10.1136/adc.2003.037309

See end of article for authors' affiliations

.....................

Correspondence to: Dr Resch, Division of Neonatology, Department of Paediatrics, University Hospital Graz, Auenbruggerplatz 30, 8036 Graz, Austria; bernhard.resch@ meduni-graz.at

Accepted 23 October 2003
Objective: To identify risk factors for the development of cystic periventricular leucomalacia (PVL) in twin gestation.

Design: Retrospective case-control study.

Setting: Tertiary care university hospital, Department of Paediatrics, Division of Neonatology, Graz, Austria.

Patients: Preterm twin gestations with one sibling having developed cystic PVL, diagnosed by ultrasound scans, compared with their co-twins without PVL, in hospital between 1988 and 2000.

Main outcome measures: Perinatal and postnatal risk factors for the development of PVL.

Results: Eighteen preterm twin gestations were included. Monochorionicity was evident in $47 \%$ of the pregnancies, and twin to twin transfusion syndrome occurred in two cases (11\%). Fetal distress correlated inversely with PVL $(15 \% \vee 53 \%, p=0.019$, relative risk $(R R)=2.057,95 \%$ confidence interval $(\mathrm{Cl})=1.067$ to 3.968). Hypocarbia with $\mathrm{PCO}_{2}$ levels below $30 \mathrm{~mm} \mathrm{Hg}(4 \mathrm{kPa})$ was diagnosed in $29 \%$ of the cases compared with $6 \%$ of the controls $(p=0.038, R R=1.944,95 \% \mathrm{Cl}=1.113$ to 3.396). There were no significant differences between groups with regard to premature rupture of the membranes, early onset infection, respiratory distress syndrome, mechanical ventilation, arterial hypotension, persistent ductus arteriosus, and hyperbilirubinaemia. Asphyxia was only evident in three controls. Three infants died and another three were lost to follow up. None of the cases compared with $62 \%$ of the controls were diagnosed as having developed normally $(p<0.001)$, and 14 cases $(82 \%)$ compared with two controls (15\%) developed cerebral palsy ( $<<0.001)$.

Conclusion: Hypocarbia was the only risk factor strongly associated with cystic PVL. The general outcome of the infants was poor.

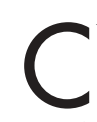
ystic periventricular leucomalacia (PVL) is the most severe and common cause of cerebral palsy in children surviving preterm birth. Although the pathogenesis of PVL is not completely understood, most theories consider the necroses of the white matter in their typical periventricular distribution to be hypoxic-ischaemic lesions resulting from impaired perfusion at the vascular border zones between the ventriculopedal and ventriculofugal arteries. ${ }^{1}$ A contrasting view focuses on the role of intrauterine infection with direct toxic effects on fetal oligodendrocytes and astrocytes by cytokines (interleukin $1 \beta$, interleukin 6 , and tumour necrosis factor $\alpha) .^{2}$ Many risk factors for the development of cystic PVL have been identified including prematurity, asphyxia, respiratory distress, ${ }^{34}$ septicaemia, ${ }^{3-6}$ chorioamnionitis and premature rupture of the membranes (PROM), , ${ }^{26-13}$ maternal haemorrhage, arterial hypotension, ${ }^{314}$ persistent ductus arteriosus, ${ }^{3}{ }^{15}$ hypocarbia, ${ }^{16-20}$ and multiple gestation. ${ }^{7} 101321$

During the last decade, multiple gestations have increased, mainly because of medically assisted reproductive techniques. ${ }^{22}$ Multiple pregnancy has been identified as an important risk factor for the development of cystic PVL and cerebral palsy. ${ }^{71} 13^{21} 23-25$ The increased risk of cerebral palsy in the case of multiple gestations is not entirely explained by the increased risk of prematurity or low birth weight. ${ }^{25}$ Other explanations include intrauterine growth retardation, ${ }^{24}$ vascular factors, such as imbalanced placental blood supply, ${ }^{26}$ and specific problems such as twin to twin transfusion and intrauterine death of the co-twin. ${ }^{23} 2627$

The aim of the study was to identify various perinatal and postnatal factors that may contribute to the development of cystic PVL by comparing the preterm twin with PVL with the co-twin without PVL.

\section{MATERIALS AND METHODS}

This study is a retrospective analysis of preterm twin gestations admitted to the Division of Peripartal Paediatrics and Division of Neonatology of the Department of Paediatrics of the University Hospital of Graz, Austria, between 1988 and 2000. Inclusion criteria were diagnosis of cystic PVL by ultrasound (US) examination in one twin and no evidence of periventricular echodensities (PVEs) or cystic PVL in the COtwin within 10 days of life. The medical records, US scans, and data from our neurodevelopmental follow up outpatient clinic were reviewed. Patients were diagnosed by our local computer assisted diagnosis system (installed since 1988) by coding PVEs, PVL, and multiple gestation.

Cranial US scans were routinely obtained in all preterm infants on days 1,3 , and 5 , and thereafter once a week in the case of pathological findings, and always at discharge (3640 weeks corrected age). Real time US scans were performed with a commercially available unit (Advanced Technology Laboratories Inc, Bothell, Washington, USA) using a 7.5 MHz transducer, and multiple images were obtained in the coronal and sagittal planes through the anterior fontanelle. The US scans were reviewed for the diagnosis and onset of PVEs and cystic PVL, according to the classification of de Vries et al. ${ }^{28}$ PVEs were defined as confluent areas of increased echogenicity comparable to the echogenicity of the choroid plexus. The diagnosis of cysts was confirmed in both the coronal and sagittal planes. Unilateral or bilateral location and anterior

Abbreviations: I/PVL, intra/periventricular haemorrhage; PROM, premature rupture of the membranes; PVE, periventricular echodensity; PVL, periventricular leucomalacia; SGA, small for gestational age; US, ultrasound 
(A), parietal (P), and occipital $(\mathrm{O})$ location were documented, and the maximum diameter of the single largest cyst was measured. In addition, day of diagnosis of PVEs, day of diagnosis of cysts, number of US examinations up to the first diagnosis of cysts, and total number of US examinations were recorded.

For the analysis of risk factors, twins with cystic PVL were compared with their co-twins without PVL. Perinatal characteristics included birth weight, birth weight discordance, small for gestational age (SGA), sex, birth order, breech presentation, caesarean section, risks during labour including abruptio placentae, umbilical cord anomalies, and fetal distress (pathological intrapartum cardiotocography, meconium stained amniotic fluid), type of placentation, PROM, chorioamnionitis, twin to twin transfusion syndrome, Apgar scores, umbilical artery $\mathrm{pH}$, and capillary $\mathrm{pH}$ less than 30 minutes after birth. Postnatal characteristics included asphyxia, early onset infection, arterial hypotension, persistent ductus arteriosus, hyperbilirubinaemia, days of mechanical ventilation, hypocarbia, respiratory distress syndrome, apnoeas, neonatal seizures, hypoxic-ischaemic encephalopathy, cerebral infarction, intra/periventricular haemorrhage (I/PVH) and posthaemorrhagic hydrocephalus.

Birth weight discordance (percentage) was defined as follows: ${ }^{29}$

((Birth weight of larger twin - birth weight of smaller twin)/birth weight of larger twin) $\times 100$.

PROM was defined as onset before labour. Clinical chorioamnionitis was diagnosed according to the definition of Baud et al. ${ }^{9}$ Monochorionic placentation was diagnosed by the obstetrician by placental examination after birth. Twin to twin transfusion syndrome was diagnosed by antenatal US examination as described by Wittmann et al. ${ }^{30}$ Asphyxia was characterised by fetal distress, an Apgar score of 5 or less after five minutes, and an umbilical artery pH less than 7.10. Diagnosis of early onset infection included clinical signs of sepsis with positive blood culture and/or a positive sepsis score $^{31}$ within the first 72 hours of life. Arterial hypotension was defined as a mean arterial blood pressure, measured with a Dinamap, below 95\% limits ${ }^{32}$ and requiring treatment. Hypocarbia was defined as an arterial carbon dioxide partial pressure $\left(\mathrm{PCO}_{2}\right)$ less than $30 \mathrm{~mm} \mathrm{Hg}$ for at least one hour. Diagnosis of hypoxic-ischaemic encephalopathy included neurological abnormalities occurring during the first 24 hours of life as described by Sarnat and Sarnat ${ }^{33}$ following asphyxia as described above. Neonatal seizures were defined as paroxysmal alterations in neurological function (subtle, tonic, clonic, or myoclonic), with autonomic nervous system changes and different from the symmetrical tremor of jitteriness.

For neurodevelopmental outcome, infants were examined at the corrected for prematurity age of $4,8,12,18$, and 24 months, and thereafter once a year. Outcome was assessed using developmental tests as described by Griffith $^{34}$ in the first 2 years of life and those described by Kaufman and Kaufman $^{35}$ above this age, and neurological examinations as described by Amiel-Tison and Stewart $^{36}$ and Touwen. ${ }^{37}$ Classification of mental outcome included normal, developmental delay, and mental retardation. Classification of neurological outcome included normal, minor neurological abnormalities (dystonia, hypotonia, asymmetry), and cerebral palsy including hemiplegia (one side of body, arm more than leg), diplegia (minimal upper extremity involvement, legs more impaired), and tetraplegia (severe involvement of all extremities, legs more than arms). Classification of visual disorders included normal, strabismus, and severe visual impairment. Hearing deficiency and dyslalia were also diagnosed. Other findings included microcephaly and dystrophy.
Statistical analyses were performed using the $t$ test and Wilcoxon test for numerical data and the $\chi^{2}$ test using Yates correction and Fisher's exact test as appropriate for categorical data. For all statistical tests, a level of significance of 0.05 was used. Multivariate analysis was performed with a logistic regression model (Sysstat 8.0; SPSS Inc, Chicago, Illinois, USA, 1998). Relative risks and 95\% confidence intervals were calculated using the software package CIA (Confidence Interval Analysis; version 2.0.0: Statistics with confidence; London: BMJ Publishing Group, 2000).

\section{RESULTS}

During the study period, 276 twin gestations ( $\leqslant 35$ weeks gestational age) were admitted to one of our two neonatal wards. Their mean (SD) gestational age was 32 (2.8) weeks (range 24-35), and their mean (SD) birth weight was 1614 (542) g (range 450-3000). Twenty one preterm twin gestations $(7.6 \%)$ had a diagnosis of cystic PVL. Eighteen twins fulfilled the inclusion criteria. In three cases both twins had developed cystic PVL.

Diagnosis of PVEs occurred at median day 2 (range 1-6), and diagnosis of cysts at median day 20 (range 10-32). The total median number of US examinations per patient was 10 (range 6-14), the median number of examinations up to the diagnosis of cysts was 4 (range 2-7). The median latency period between last US examination and diagnosis of cysts was five days (range two to seven). Bilateral location of the cysts was diagnosed in 15 infants (88\%), and cysts were predominantly located parieto-occipital (APO/PO) in 13 infants $(72 \%)$. The median maximum diameter of the single largest cyst was $10 \mathrm{~mm}$ (range 4-24). Five infants developed cysts within 14 days, suggesting an antenatal origin of the cerebral damage, a perinatal origin was suspected in four cases (diagnosis of cysts between 13 and 20 days), and a postnatal origin in the remaining nine cases including those with hypocarbia.

Table 1 shows the prenatal and maternal characteristics of the 18 preterm twin gestations. There was a birth weight discordance of more than $30 \%$ in three cases $(57 \%, 44 \%$, and $33 \%$ ). The infants with higher birth weight (1840 g, $2100 \mathrm{~g}$, and 1090 g respectively) were all diagnosed as having cystic PVL and all developed cerebral palsy. The infants with lower birth weight (790 g, $1180 \mathrm{~g}$, and $726 \mathrm{~g}$, respectively) did not develop cerebral palsy (two of them were SGA). Twin to twin transfusion syndrome occurred in two of the seven monochorionic pregnancies $(29 \%)$. In both cases, the recipient developed cystic PVL and cerebral palsy. One of the donors died at day 18 following multiorgan failure caused by early onset sepsis, and the other one developed normally. In two cases (11\%) the co-twins also developed cerebral palsy, one as the result of cerebral infarction, the other one because of I/PVH.

\begin{tabular}{|c|c|}
\hline Gestational age (weeks) & $30(2.7)(26-35)$ \\
\hline Maternal age (years) & $29.7(4.7)(20-35)$ \\
\hline Number of pregnancies & $2.6(1.1)(1-4)$ \\
\hline History of abortion & $7(39)$ \\
\hline In vitro fertilisation & 3 (17) \\
\hline Maternal haemorrhage & $3(17)$ \\
\hline Pre-eclampsia & $2(11)$ \\
\hline Maternal steroids & $13(72)$ \\
\hline Chorioamnionitis & $6(33)$ \\
\hline Monochorionic placentation & $7 / 15(47)$ \\
\hline Birth weight discordance (>30\%) & $3(17)$ \\
\hline Twin to twin transfusion syndrome & $2(11)$ \\
\hline
\end{tabular}


Table 2 Perinatal characteristics of 18 preterm twins with cystic PVL compared with their 18 co-twins without cystic PVL

\begin{tabular}{lllll}
\hline Characteristic & PVL group & Controls & p Value & Relative risk (95\% CI) \\
\hline Birth weight & $1459(550)$ & $1290(507)$ & $\mathrm{ns}$ & - \\
SGA & 0 & $3(17 \%)$ & $\mathrm{nc}$ & - \\
Male & $10(56 \%)$ & $12(67 \%)$ & $\mathrm{nc}$ & - \\
1st twin & $11(61 \%)$ & $7(39 \%)$ & 0.1 & $1.571(0.791$ to 3.122) \\
2nd twin & $7(39 \%)$ & $11(61 \%)$ & - & - \\
Breech presentation & $4(22 \%)$ & $7(39 \%)$ & $\mathrm{ns}$ & - \\
Caesarean section & $10(56 \%)$ & $10(56 \%)$ & $\mathrm{nc}$ & - \\
Risks during labour & $2(11 \%)$ & $5(28 \%)$ & $\mathrm{ns}$ & - \\
PROM & $4(22 \%)$ & $6(33 \%)$ & $\mathrm{ns}$ & - \\
Hours (PROM-birth) & $61(72)$ & $25(19)$ & $\mathrm{ns}$ & - \\
Fetal distress & $2 / 13(15 \%)$ & $8 / 15(53 \%)$ & 0.019 & 2.057 (1.067 to 3.968) \\
Apgar 1 minute & $6.6(2.4)$ & $5.9(2.9)$ & $\mathrm{ns}$ & - \\
Apgar 5 minutes & $8.8(1.1)$ & $8.3(1.4)$ & $\mathrm{ns}$ & - \\
Apgar 10 minutes & $9.4(0.7)$ & $8.9(1.3)$ & $\mathrm{ns}$ & - \\
Umbilical artery pH & $7.30(0.08)$ & $7.26(0.11)$ & $\mathrm{ns}$ & - \\
Capillary pH & $7.19(0.05)$ & $7.21(0.07)$ & $\mathrm{ns}$ & - \\
\hline
\end{tabular}

Data are presented as $n(\%)$ or mean (SD).

ns, Not significant; nc, not calculated; SGA, small for gestational age; PROM, premature rupture of the membranes; PVL, periventricular leucomalacia.

Table 2 shows the perinatal data comparing the cases with their controls. PVL grade 2 was diagnosed in two cases $(11 \%)$, grade 3 in 15 cases $(83 \%)$, and grade 4 in one case $(6 \%)$.

Table 3 shows postnatal characteristics and neurodevelopmental follow up. Three infants without signs of PVEs or PVL died within 28 days of life, two after severe I/PVH, and one after multiorgan failure. Table 4 shows the association of ultrasound findings with motor deficits in the cases. Two infants $(7 \%)$ developed seizure disorders combined with cerebral palsy; one of them had had neonatal seizures. Visual disorders were diagnosed in seven infants $(23 \%)$, three of them with strabismus (43\%) and four with severe visual impairment (57\%). Hearing deficiency was diagnosed in one infant without cerebral palsy, and dyslalia in another one. Other findings were microcephaly in one control with hemiplegia following cerebral infarction, and dystrophy in five infants. Neurodevelopmental outcome differed significantly between the groups. None of the cases developed normally. Fourteen of 17 cases (82\%) compared with two of 13 controls (15\%) had a diagnosis of cerebral palsy $(p<0.001)$, and eight $(44 \%)$ versus none had a diagnosis of mental retardation $(\mathrm{p}<0.001)$ (table 3$)$. In the case of cerebral palsy, infants always had cysts located parietal and/ or occipital. In eight cases there was a history of $\mathrm{I} / \mathrm{PVH}$ (germinal matrix haemorrhage in seven cases, IVH grade 2 in one case), of whom six (75\%) developed cerebral palsy in contrast with seven controls with $\mathrm{I} / \mathrm{PVH}$, of whom only one infant (14\%) developed cerebral palsy (this infant developed posthaemorrhagic hydrocephalus). Cerebral infarction occurred in one control developing hemiplegia.

Risk factor analysis by multivariate regression analysis revealed significant differences between cases and controls with regard to fetal distress (15\% v 53\%) and hypocarbia (29\% $v 6 \%$ ); see tables 2 and 3. The mean Apgar scores at 1, 5, and 10 minutes tended to be lower in the controls. The mean birth weight of the cases tended to be higher, and more controls were SGA. Apnoeas and seizures were more common in the cases.

\section{DISCUSSION}

Our study is the first to analyse selected risk factors for the development of cystic PVL in preterm twin gestations by directly comparing infants with cystic PVL with their cotwins without PVL. Therefore we studied selected perinatal factors and focused especially on postnatal factors that may possibly influence the development of cystic PVL. We found a strong association between the occurrence of hypocarbia and the development of cystic PVL, with a twofold increased relative risk (95\% CI 1.113 to 3.396 ). The rates of respiratory distress syndrome and days of mechanical ventilation did not differ between the groups. The timing of first detection of cysts by US in these cases strongly supports a postnatal origin of cerebral damage. However, these results are somewhat limited by the fact that only a few infants were prone to hypocarbia. Thus, in most of the infants, no overt risks were found despite the fact of preterm twin gestation.

Several authors have described an association between hypocarbia and cystic PVL. ${ }^{16-20} 38$ A decrease in the arterial partial pressure of carbon dioxide causes a reduction in cerebral blood flow in both humans and most animals. Interestingly, a relation between hypocarbia and brain injury has not been observed in adults and full term newborn infants. The immature brain may be more sensitive to hypocarbia because of less developed regulation of cerebral blood flow. ${ }^{19}$ Thus hypocarbia in preterm infants is thought to cause vasoconstriction and a decrease in cerebral blood flow with subsequent hypoxic brain tissue injury ${ }^{16}{ }^{17} 19$ Kubota et $a l^{20}$ found a weaker relation between hypocarbia (values below $25 \mathrm{~mm} \mathrm{Hg}$ ) and PVL in infants with birth weights less than $1000 \mathrm{~g}$ than in infants with birth weights abovel000 g. They suggest that these very low birthweight infants may have decreased sensitivity to hypocarbia because of their treatment, including mechanical ventilation and the frequent use of indomethacin. Wiswell et al ${ }^{16}$ described an association between hypocarbia (below $25 \mathrm{~mm} \mathrm{Hg}$ during the first day of life) and cystic PVL in preterm infants treated with high frequency jet ventilation. They reported that a high rate $(31 \%$; 18 of 58 surviving infants) developed cystic PVL with cysts more than $5 \mathrm{~mm}$ in size. There were no differences in mean $\mathrm{PaCO}_{2}$ values between the groups. However, there was a significantly greater cumulative hypocarbia below a threshold of $25 \mathrm{~mm} \mathrm{Hg}$ in infants with cystic PVL (odds ratio 5.43). Okumura $e t ~ a l^{38}$ raised the question of whether hypocarbia is a cause or a result of PVL. They found no differences in ventilator settings between the groups. They suggested that the rate of spontaneous respiration in infants with PVL may be greater than in those without, assuming that respiratory coordination may be deranged in infants with PVL. In addition, they recently reported decreased resistance indices measured by Doppler ultrasonography of the pericallosal artery in patients with PVL on the first and third day of life compared with infants without PVL, but no differences in 
Table 3 Postnatal characteristics and outcome of 18 preterm twins with cystic PVL compared with their 18 co-twins without cystic PVL

\begin{tabular}{|c|c|c|c|c|}
\hline Characteristic & PVL group & Controls & p Value & Relative risk $(95 \% \mathrm{Cl})$ \\
\hline Asphyxia & 0 & $3(17 \%)$ & $\mathrm{nc}$ & - \\
\hline $\mathrm{HIE}$ & 0 & 0 & - & - \\
\hline Early onset sepsis & $5(28 \%)$ & $4(22 \%)$ & ns & - \\
\hline Arterial hypotension & $1(6 \%)$ & $2(11 \%)$ & ns & - \\
\hline PDA & $6(33 \%)$ & $5(28 \%)$ & ns & - \\
\hline Hyperbilirubinaemia & $6(33 \%)$ & $6(33 \%)$ & ns & - \\
\hline RDS & $9(50 \%)$ & $10(56 \%)$ & ns & - \\
\hline Days on ventilator & $6.9(10.1)$ & $7.4(8.7)$ & ns & - \\
\hline Hypocarbia* & $5 / 17(29 \%)$ & $1 / 17(6 \%)$ & 0.038 & 1.944 (1.113 to 3.396$)$ \\
\hline Apnoeas & $12(67 \%)$ & $8(44 \%)$ & 0.09 & $1.600(0.774$ to 3.309$)$ \\
\hline Neonatal seizures & $5(28 \%)$ & $2(11 \%)$ & 0.1 & $1.607(0.856$ to 3.019$)$ \\
\hline Cerebral infarction & 0 & $1(6 \%)$ & $\mathrm{nc}$ & - \\
\hline I/PVH & $8(44 \%)$ & $7(39 \%)$ & $\mathrm{nc}$ & - \\
\hline $\mathrm{PHH}$ & 0 & $1(6 \%)$ & $\mathrm{nc}$ & \\
\hline Follow up (months) & $52(31)$ & $29(27)$ & $\mathrm{nc}$ & - \\
\hline Normal development & 0 & $8(62 \%)$ & $<0.001$ & $\infty$ \\
\hline MNA & $2(12 \%)$ & $2(15 \%)$ & $\mathrm{nc}$ & - \\
\hline Developmental delay & $2(12 \%)$ & $1(8 \%)$ & $\mathrm{nc}$ & - \\
\hline Mental retardation & $8(44 \%)$ & 0 & $<0.001$ & $\infty$ \\
\hline Cerebral palsy & $13 / 17(76 \%)$ & $2 / 13(15 \%)$ & $<0.001$ & 3.250 (1.372 to 7.699$)$ \\
\hline \multicolumn{5}{|c|}{$\begin{array}{l}\text { Data are presented as } \mathrm{n}(\%) \text { or mean (SD). } \\
{ }^{*} \mathrm{PCO}_{2} \text { values }<30 \mathrm{~mm} \mathrm{Hg} \text { for at least one hour. } \\
\mathrm{ns}, \text { Not significant; } \mathrm{nc} \text {, not calculated; HIE, hypoxic-ischaemic encephalopathy; PDA, persistent ductus arteriosus } \\
\text { RDS, respiratory distress syndrome; I/PVH, intra/periventricular haemorrhage; PHH, posthaemorrhagic } \\
\text { hydrocephalus; MNA, minor neurological abnormalities; PVL, periventricular leucomalacia. }\end{array}$} \\
\hline
\end{tabular}

resistance index and associated hypocarbia between groups. ${ }^{39}$ Thus they could not confirm the speculation that cerebral vasoconstriction and decreased cerebral blood flow may be induced by hypocarbia.

As previously reported, ${ }^{7}$ Apgar scores and umbilical artery $\mathrm{pH}$ tended to be lower in the controls, and there was a diagnosis of asphyxia only in some controls. Some authors have reported similar observations on the occurrence of cystic PVL in infants with a relatively benign postnatal course. ${ }^{40}{ }^{41}$ We found apnoeas and seizures more often in the cases, as described elsewhere. $^{7}$ In contrast with our results, some studies have identified male sex as a risk factor for the development of cystic PVL. ${ }^{17}{ }^{42-44}$ Fetal distress occurred significantly more often in our controls, in contrast with the findings of Ito et al. ${ }^{45}$ Intrauterine growth retardation has been thought to be associated with cerebral palsy in twins, ${ }^{24}$ but in neither this nor another recent study ${ }^{7}$ could we confirm this association between SGA and cerebral palsy. In this study, we found no significant effects of risk factors well known to be associated with cystic PVL in singletons, such as chorioamnionitis and PROM, ${ }^{24136-1146}$ hyperbilirubinaemia, ${ }^{6}{ }^{18}$ asphyxia, ${ }^{4}$ arterial hypotension, ${ }^{314}$ persistent ductus arteriosus, ${ }^{3}{ }^{15}$ acidosis at birth, ${ }^{47}$ and SGA and low birth weight. ${ }^{23}{ }^{25}$ The incidence of PVL and additional I/PVH (50\%) was comparable to that reported recently. ${ }^{7}$

Monochorionic placentation was observed in seven of 15 (47\%) twin gestations. Several authors have described a strong correlation between monochorionic placentation in twin pregnancies and cystic PVL or cerebral palsy. ${ }^{26} 27{ }^{46}$ Placental vascular anastomoses are common in monochorionic

Table 4 Ultrasound documentation and neurological outcome (motor deficits) of 18 preterm twins with cystic PVL

\begin{tabular}{|c|c|c|c|c|c|c|c|c|c|}
\hline Patient/Year & $\begin{array}{l}\text { PVEs } \\
\text { (day) }\end{array}$ & $\begin{array}{l}\text { Cysts } \\
\text { (day) }\end{array}$ & $\begin{array}{l}\text { Latency period } \\
\text { (days)* }^{*}\end{array}$ & $\begin{array}{l}\text { Location } \\
(\mathrm{A} / \mathrm{P} / \mathrm{O} ; \mathrm{L} / \mathrm{R} / \mathrm{B}) \dagger\end{array}$ & $\operatorname{Max} \mathrm{DM}(\mathrm{mm}) \ddagger$ & $\begin{array}{l}\text { Number of } \\
\text { US exams }\end{array}$ & GMH/IVHब & $\begin{array}{l}\text { Follow up } \\
\text { (age in years) }\end{array}$ & Outcome§ \\
\hline $1 / 1988$ & 2 & 26 & 6 & $\mathrm{APO} ; \mathrm{B}$ & 24 & 11 & 1 & 11.5 & DP \\
\hline $2 / 1991$ & 1 & 24 & 4 & $\mathrm{APO} ; \mathrm{B}$ & 19 & 11 & 1 & 2 & Ataxia \\
\hline $3 / 1993$ & 2 & 30 & 5 & $\mathrm{PO} ; \mathrm{L}$ & 10 & 14 & 1 & 7.5 & HP \\
\hline $4 / 1994$ & 2 & 24 & 7 & $\mathrm{PO} ; \mathrm{B}$ & 8 & 10 & 0 & 7 & Dystonia \\
\hline $5 / 1994$ & 1 & 32 & 6 & $\mathrm{P} ; \mathrm{B}$ & 10 & 9 & 0 & 3 & DP \\
\hline $6 / 1994$ & 2 & 26 & 5 & $\mathrm{O} ; \mathrm{B}$ & 8 & 8 & 0 & 6.5 & DP \\
\hline $7 / 1995$ & 1 & 19 & 6 & $\mathrm{APO} ; \mathrm{B}$ & 6 & 6 & 1 & 6.5 & DP \\
\hline $8 / 1995$ & 1 & 20 & 5 & $O ; B$ & 6 & 8 & 0 & 4.5 & DP \\
\hline $9 / 1995$ & 2 & 22 & 4 & $\mathrm{APO} ; \mathrm{B}$ & 12 & 9 & 0 & Lost to follow-up & \\
\hline $10 / 1996$ & 1 & 11 & 3 & $\mathrm{P} ; \mathrm{B}$ & 4 & 13 & 0 & 2.25 & DP \\
\hline $11 / 1996$ & 2 & 19 & 6 & $\mathrm{PO} ; \mathrm{B}$ & 9 & 10 & 1 & 3 & DP \\
\hline $12 / 1996$ & 6 & 23 & 7 & $\mathrm{O} ; \mathrm{B}$ & 8 & 6 & 1 & 3.5 & DP \\
\hline $13 / 1997$ & 3 & 23 & 3 & $\mathrm{APO} ; \mathrm{B}$ & 22 & 12 & 0 & 4 & DP \\
\hline $14 / 1997$ & 2 & 20 & 5 & PO; L & 6 & 10 & 1 & 2 & normal \\
\hline $15 / 1999$ & 1 & 15 & 6 & $\mathrm{APO} ; \mathrm{B}$ & 12 & 7 & 0 & 3 & DP \\
\hline $16 / 1999$ & 1 & 15 & 8 & $\mathrm{APO} ; \mathrm{B}$ & 14 & 7 & 0 & 2.5 & DP \\
\hline $17 / 2000$ & 3 & 17 & 5 & $\mathrm{APO} ; \mathrm{B}$ & 15 & 8 & 0 & 3 & TP \\
\hline $18 / 2000$ & 1 & 10 & 3 & $\mathrm{APO} ; \mathrm{B}$ & 15 & 13 & 1 & 2 & DP \\
\hline
\end{tabular}

*Period between last US examination and first diagnosis of cysts.

$\dagger \mathrm{A}$, Anterior; $\mathrm{P}$, parietal; $\mathrm{O}$, occipital; L, left sided; $\mathrm{R}$, right sided; $\mathrm{B}$, bilateral.

$\ddagger$ Maximum diameter of a single cyst.

-Germinal matrix/intraventricular haemorrhage.

§Motor deficits: DP, diplegia; HP, hemiplegia; TP, tetraplegia.

PVL, Periventricular leucomalacia; PVE, periventricular echodensity. 
infants. ${ }^{26}$ These anastomoses can lead to twin to twin transfusion syndrome, which we observed in two of seven $(29 \%)$ monochorionic pregnancies, as compared with 15\% reported by Sebire et al..$^{48}$ Our findings confirm that the recipient twin is at increased risk of developing cystic PVL and cerebral palsy. ${ }^{49}{ }^{50}$ Even if there are no clinical signs of twin to twin transfusion syndrome, placental vascular connections, especially vein to vein anastomoses, may produce transitory cardiovascular compromise in one or both twins, resulting in impaired cerebral perfusion and brain damage. ${ }^{26}$

We observed a significant birth weight discordance of more than $30 \%$ in three twin pairs. The infants with higher birth weight all developed cystic PVL and subsequently cerebral palsy. The infants with the lower birth weight did not develop cystic PVL or cerebral palsy. Cheung et al ${ }^{29}$ found a higher incidence of PVL in the group of infants with birth weight discordance, but not in the groups of smaller and larger birth weight. They proposed that the difference in growth between the fetuses may be associated with changes in their haemodynamic status, and that may affect the oxygen supply to the fetal brain.

In contrast with Baud et al, ${ }^{9}$ we found no association between mode of delivery and the development of cystic PVL. Furthermore we found no association between breech presentation and cystic PVL, which was in accordance with Baud et al. We found no effect of birth order on subsequent risk of brain damage, in accordance with other authors. ${ }^{24} 25$ There have been many suggestions about the influence of various risk factors on the development of cystic PVL, but we were unable to show a correlation between the possible timing of PVL and its cause except for hypocarbia and postnatal origin of cerebral damage.

Our results suggest that postnatal factors such as hypocarbia may have an important role in the development of cystic PVL in preterm twin gestations. Therefore mechanical ventilation of infants at high risk of PVL should be monitored carefully to avoid low $\mathrm{PCO}_{2}$ levels. On the other hand, we do not know exactly to what extent prepartal factors such as placentation contribute to its pathogenesis, which requires further investigation.

\section{Authors' affiliations}

B Resch, A Jammernegg, U Maurer, W D Mueller, Division of Neonatology, Department of Paediatrics, University Hospital Graz, Austria

E Vollaard, University Hospital Groningen, the Netherlands B Pertl, Department of Obstetrics and Gynaecology, University Hospital Graz

\section{REFERENCES}

1 Volpe JJ. Neurology of the newborn. Philadelphia: WB Saunders, 2001:217-497.

2 Damman O, Levinton A. Maternal intrauterine infection, cytokines, and brain damage in the preterm newborn. Pediatr Res 1997;42:1-8.

3 Sinha SK, Davies JM, Sims DG, et al. Relation between periventricular haemorrhage and ischaemic brain lesions diagnosed by ultrasound in very preterm infants. Lancet 1985;2:1154-5.

4 Yoon BH, Romero R, Yang SH, et al. Interleukin-6 concentrations in umbilical cord plasma are elevated in neonates with white matter lesions associated with periventricular leukomalacia. Am J Obstet Gynecol 1996;174:1433-40.

5 De Vries LS, Levene MI. Cerebral ischaemic lesions. In: Levene MI, Bennet MJ, Punt J, eds. Fetal and neonatal neurology and neurosurgery. Edinburgh: Churchill Livingstone, 1988:326-38.

6 Trounce JQ, Shaw DE, Levene MI, et al. Clinical risk factors and periventricular leukomalacia. Arch Dis Child 1998;63:17-22.

7 Resch B, Vollaard E, Maurer U, et al. Risk factors and determinants of neurodevelopmental outcome in cystic periventricular leucomalacia. Eur J Pediatr 2000;159:663-70.

8 Alexander JM, Gilstrap LC, Cox SM, et al. Clinical chorioamnionitis and the prognosis for very low birth weight infants. Obstet Gynecol 1998;91:725-9.

9 Baud O, Ville Y, Zupan V, et al. Are neonatal brain lesions due to intrauterine infection related to mode of delivery? Br J Obstet Gynaecol 1998; 105:121-4.
10 Bejar R, Wozniak $P$, Allard $M$, et al. Antenatal origin of neurologic damage in newborn infants. I. Preterm infants. Am J Obstet Gynecol 1988; 159:357-63.

11 Verma U, Tejani N, Klein S, et al. Obstetric antecedents of intraventricular haemorrhage and periventricular leukomalacia in the low-birth-weight neonate. Am J Obstet Gynecol 1997; 177:275-81.

12 Yoon BH, Romero R, Kim CJ, et al. High expression of tumor necrosis factoralpha and interleukin-6 in periventricular leukomalacia. Am J Obstet Gynecol 1997; 177:406-11.

13 Zupan V, Gonzalez P, Lacaze-Masmontail T, et al. Periventricular leukomalacia: risk factors revisited. Dev Med Child Neurol 1998:38:1061-7.

14 Calvert SA, Hoskins EM, Fong KW, et al. Etiological factors associated with the development of periventricular leukomalacia. Acta Paediatr Scand 1987;76:254-9.

15 De Vries LS, Reger R, Dubowitz LM, et al. Perinatal risk factors for the development of extensive cystic leukomalacia. Am J Dis Child 1988; 142:732-5

16 Wiswell TE, Graziani $\amalg$, Kornhauser MS, et al. Effects of hypocarbia on the development of cystic periventricular leukomalacia in premature infants treated with high-frequency jet ventilation. Pediatrics 1996;98:918-24.

17 Fujimoto S, Togari H, Yamaguchi N, et al. Hypocarbia and cystic periventricular leukomalacia in premature infants. Arch Dis Child 1994;71:F107-10.

18 Ikonen RS, Janas MO, Koivikko MJ, et al. Hyperbilirubinemia, hypocarbia and periventricular leukomalacia in preterm infants: relationship to cerebral palsy. Acta Pediatr Scand 1992;81:802-7.

19 Greisen G, Vannucci RC. Is periventricular leucomalacia a result of hypoxicischaemic injury? Hypocapnia and the preterm brain. Biol Neonate 2001;79:194-200.

20 Kubota H, Ohsone Y, Oka F, et al. Significance of clinical risk factors of cystic periventricular leukomalacia in infants with different birthweights. Acta Paediatr 2001;90:302-8.

21 Goetz MC, Gretebeck RJ, Oh KS, et al. Incidence, timing, and follow-up of periventricular leukomalacia. Am J Perinatol 1995;12:325-7.

22 Stanley A, ed. Multiple pregnancy and delivery. St. Louis: Mosby, 1996.

23 Grether JK, Nelson KB, Cummins SK. Twinning and cerebral palsy: experience in four Northern California counties, births 1983 through 1985. Pediatrics 1993:92:854-8.

24 Laplaza FJ, Root L, Tassanawipas A, et al. Cerebral palsy in twins. Dev Med Child Neurol 1992;34:1053-63.

25 Williams K, Hennessy E, Alberman E. Cerebral palsy: effects of twinning, birthweight, and gestational age. Arch Dis Child 1996;75:F178-82.

26 Bejar R, Vigliocco G, Gramajo H, et al. Antenatal origin of neurologic damage in newborn infants. II. Multiple gestations. Am J Obstet Gynecol 1990; 162:1230-6.

27 Pharoah POD. Twins and cerebral palsy. Acta Paediatr 2001;436(suppl):6-10.

28 De Vries LS, Eken P, Dubowitz MS, et al. The spectrum of leukomalacia using cranial ultrasound. Behav Brain Res 1992;49:1-6.

29 Cheung VYT, Bocking AD, Dasilva OP. Preterm discordant twins: what birth weight difference is significant? Am J Obstet Gynecol 1995;172:955-9.

30 Wittmann BK, Baldwin VJ, Nichol B. Antenatal diagnosis of twin transfusion syndrome by ultrasound. Obstet Gynecol 1981;58:123-7.

31 Philipps AGS, Hewitt JR. Early diagnosis of neonatal sepsis. Pediatrics 1980;56:1036-41.

32 Low JA, Froese AB, Smith JT, et al. Blood pressure and heart rate of the preterm newborn following delivery. Clin Invest Med 1991;14:183-7.

33 Sarnat HB, Sarnat SM. Neonatal encephalopathy following fetal distress. A clinical and electroencephalographic study. Arch Neurol 1976;33:696-705

34 Griffith A. The abilities of babies. London: University of London Press, 1970.

35 Kaufman AS, Kaufman NL. Kaufman assessment battery for children. German version. Amsterdam, Lisse, Frankfurt am Main: Swets Zeitlinger BV, 1991.

36 Amiel-Tison C, Stewart AL. Follow-up studies in the first five years of life: a pervasive assessment of neurological function. Arch Dis Child 1989;64:496-502

37 Touwen BCL. Neurological development in infancy. London: Heinemann Medical Books, 1976.

38 Okumura A, Hayakawa F, Kato T, et al. Hypocarbia in preterm infants with periventricular leukomalacia: the relation between hypocarbia and mechanical ventilation. Pediatrics 2001;107:469-75.

39 Okumura A, Toyota N, Hayakawa F, et al. Cerebral hemodynamics during early neonatal period in preterm infants with periventricular leukomalacia. Brain Dev 2002;24:693-7.

40 Perlman JM, Risser R. Relationship of uric acid concentrations and severe intraventricular haemorrhage/leukomalacia in the premature infant. J Pediatr 1998;132:436-9.

41 Perlman JM, Risser R, Broyles RS. Bilateral cystic periventricular leukomalacia in the preterm infant: associated risk factors. Pediatrics 1996;97:822-7.

42 Fazzi E, Orcesi S, Caffi L, et al. Neurodevelopmental outcome in preterm infants with periventricular leukomalacia. Neuropediatrics 1994;25:134-9.

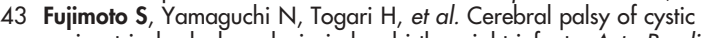
periventricular leukomalacia in low birth-weight infants. Acta Paediatr 1994;83:397-401.

44 Rogers B, Msall M, Owens T, et al. Cystic periventricular leukomalacia and type of cerebral palsy in preterm infants. J Pediatr 1994;125:1-8.

45 Ito T, Kadowaki K, Takahashi H, et al. Clinical features of and cardiotocographic findings for premature infants with antenatal periventricular leukomalacia. Early Hum Dev 1997;47:195-201. 
46 Burguet A, Monnet E, Pauchard JY, et al. Some risk factors for cerebral palsy in very premature infants: Importance of premature rupture of membranes and monochorionic twin placentation. Biol Neonate 1999;75:177-86

47 Spinillo A, Capuzzo E, Stronati M, et al. Obstetric risk factors for periventricular leukomalacia among preterm infants. Br J Obstet Gynaecol 1998; 105:865-71.
48 Sebire NJ, Souka A, Skentou H, et al. Early prediction of severe twin-to-twin transfusion syndrome. Hum Reprod 2000; 15:2008-10.

49 Haverkamp F, Lex C, Hanisch C, et al. Neurodevelopmental risks in twin-totwin transfusion syndrome: preliminary findings. Eur J Paediatr Neurol 2001:5:21-7.

50 Larroche JC, Droullé P, Delezoide AL, et al. Brain damage in monozygous twins. Biol Neonate 1990;57:261-78.

\section{IMAGES IN NEONATAL MEDICINE}

\section{A complication worth remembering}

7

his neonate developed progressive abdominal distension after long line insertion requiring high ventilating pressures. A linogram revealed leakage of contrast into the peritoneum. After long line removal, the child was extubated in 48 hours.

This complication should be considered when abdominal distension occurs without convincing evidence of necrotising enterocolitis.

N B Soni, A Selby, P Minchom SpR Paediatrics, Glan Clwyd Hospital, Rhyl, Wales, UK; nbsoni@hotmail.com

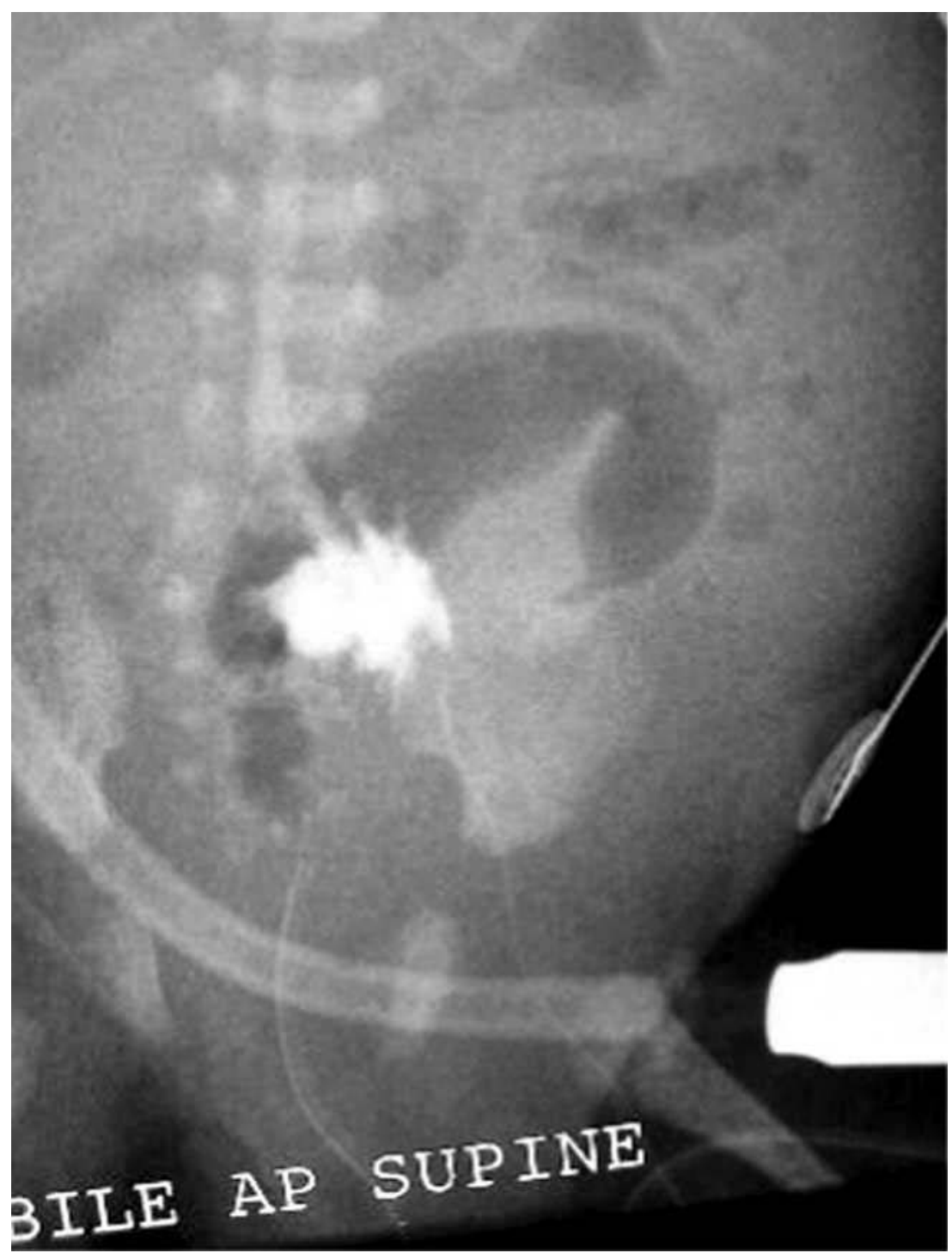

Figure 1 Linogram showing contrast leakage into peritoneum. 